\title{
Measuring Internal Migration Among the Foreign-Born: Insights from Canadian Data
}

\author{
K. Bruce Newbold*
}

\begin{abstract}
As the most important avenue of spatial population change and redistribution, how migration events are defined alters the empirical measurement and the derived conclusions. Using the foreign-born population as an example and drawing upon recent Canadian census files, this paper explores two related issues. First, the problems and fallacies of attempting to extrapolate temporal trends from period-specific measures are highlighted. Second, measurement issues associated with the length of the migration interval are evaluated by defining return and onward migrations within the foreign-born population based upon one- and five-year migration measures.
\end{abstract}

\section{INTRODUCTION}

In recent years, immigration has once again become a prominent national policy issue within Canada's political and academic arenas, as demonstrated by the Metropolis project (see, for example, the annotated bibliography by Kobayashi and Peake 1997 and recent work by Beaujot 1998; Bourne 1999; Lo and Wang 1999). Worries include the adjustment of immigrants to Canadian society (Fong and Wilkes 1999; Kazemipur and Halli 1999), immigrant upon native impacts (Bourne 1999), public service provision (Lo and Wang 1999; Harvey, Reil, and Siu 1999), and the changing demographic profile of the Canadian population and urban areas (Beaujot 1991; Bourne 1999; Majury 1994). Vietnamese refugees, for example, had largely relocated to urban areas in the decade following their arrival in Canada, creating identifiable enclaves (Olson and Kobayashi 1993), while recent Chinese immigrants have settled within suburban locales, creating relatively complete local economies (Lo and Wang 1999).

Embedded within these issues are questions that relate to the distribution and redistribution of the immigrant population and that impinge upon service provision, immigrant adjustment within Canada, and the design of policies to assist that adjustment. As the most important avenue of spatial population change and redistribution, the internal migration of this population assumes a potentially important role as immigrants adjust to their host country, particularly in the period immediately after arrival (Newbold 1999). Yet, how migration is defined, which includes the length of the migration interval and the composition of the sample population, alters the empirical measurement of migration and the derived conclusions. Of these two effects, the impact of the migration interval, including the "one- and five-year" problem, is undoubtedly well known given the attention that researchers have focused upon it (see, for example, Bell 1996; Kitsul and Philipov

* School of Geography and Geology, McMaster University, Hamilton, Ontario. This research was funded by a fellowship from the Social Sciences Research Council. 
1981; Long 1988; Morrison 1971; Rogerson 1990). Relatively less is known about the propensity for the foreign-born to engage in return or onwards migration over the short term given the reliance upon place of birth data in past studies (i.e., Newbold and Liaw 1990,1994). The ability to define these repeat migration events based upon fixed interval data (i.e., Bell 1996) would provide the opportunity to further understand migration within the foreign-born population.

Of particular importance when studying the foreign-born population and their migration behavior is that of its composition (Myers and Lee 1996). Composition reflects a set of issues, including period of arrival, immigrant status (i.e., landed immigrant or refugee), and the national origin of new arrivals. These nonexclusive effects capture changing immigration laws, including the liberalization of immigration policy by the Canadian government in 1962 that encouraged immigration from nontraditional source countries and the introduction of the "points" system in 1967. In 1957, for example, 95 percent of all immigrants were from Europe or the U.S., with the largest single group represented by the United Kingdom. By 1990, U.S. and U.K. origins accounted for only 29 percent of new arrivals, while the leading origin countries had shifted to Hong Kong, Poland, Lebanon, India, Vietnam, and the Philippines, with each group experiencing different settlement processes and reception (Bourne and Ley 1993). Proportionately, Europeans still represent the largest share of the immigrant population, but tend to be older and to have arrived in Canada earlier (Kobayashi, Moore, and Rosenberg 1998). More recently, the federal government has also placed an increasing emphasis on economic and independent immigrants (Statistics Canada 1999). The effect of shifting origins and evolving legislation is also reflected in the distribution of groups across space, echoing group cohesion (or the lack of) and existing co-ethnic concentrations along with the traditional motivation of economic opportunities. Federal multicultural policies, first enacted in 1971 under Prime Minister Trudeau, have also influenced immigrant settlement and internal migration through the allowance of the expression and preservation of ethnocultural affiliations.

Compositional effects are particularly important when investigating questions pertaining to the adjustment of immigrants over time, with many studies typically relying upon a single census period to capture what is an inherently dynamic process. In opposition to the impression of a "static" system that is realized within many studies (important exceptions include Lieberson and Waters 1987, Belanger and Rogers 1992, and Walker and Hannan 1989), the settlement system is likely a complex process that evolves over time as immigrants respond to societal and individual pressures and opportunities (Newbold 1999). In fact, the multiple dimensions of change are not observable through a single census.

The study of immigration and adjustment is about time as it is played out through space and the foreign-born population is redistributed. Consequently, failing to account for these effects may result in biased or misleading conclusions. Using the foreign-born population as an illustrator and drawing upon Canadian census data files, the purpose of this paper is to illustrate compositional and 
length of interval issues relative to the measurement of migration within the foreign-born population. This is achieved two ways. First, the paper explores the role of composition upon measures of migration. Starting with traditional period indices of migration that define migration over a five-year interval, the paper will identify the problems and fallacies of attempting to extrapolate temporal trends from these measures. Alternative measures through which migration may be visualized, including doubly defined cohort measures of migration defined by age and period of arrival, will be used.

Second, the paper investigates the impact of the length of the migration interval upon migration. Although, as mentioned above, this effect is well known, the recent inclusion of both one- and five-year measures of migration within Statistics Canada census products allows migration to be measured over shorter intervals (one year and four years, rather than five years), along with improved measures of migration events. This fixed interval data allows the definition of return and onwards migration, which had previously been based upon province of birth (i.e., Newbold and Liaw 1990, 1994) and therefore not available for the foreign-born population. Consequently, the magnitude of return and onwards migration within the foreign-born population is assessed and compared with that of the native-born population.

\section{COMPOSITIONAL EFFECTS: STATIC AND TEMPORAL INTERPRETATIONS}

Using Statistics Canada 1986, 1991, and 1996 Public Use Microdata Files (PUMF) allows migration propensities to be constructed for each census interval. Typical measures of migration and mobility based upon census products compare place of residence at the time of the census to usual place of residence five years prior, defined over specific spatial boundaries. These five-year migration rates are inherently "static" measures referring to a particular point in time, while temporal interpretations may be generated via the comparison of migration rates across census intervals. Samples from each census are restricted to the noninstitutionalized legal (landed) immigrant population ${ }^{1}$ aged five and over, with the empirical results weighted according to the rules within each census file. Three tiers of geographical movement are considered, including overall mobility rates that report the proportion of the population that moves regardless of distance (i.e., local or interprovincial). Mover rates refer to local, within census subdivision relocations, and migration rates refer to longer-distance movements that typically cross a defined border, including moves across Census subdivisions (CSDs), across Census Divisions (CDs), or provinces. Since much of the literature refers to differences in migration propensities by origin, the immigrant population was disaggregated by

\footnotetext{
${ }^{1}$ Representing when landed immigrant status was obtained, period of arrival implies some measure of commitment to Canada since applications for immigration are generally made from abroad. In fact, less than 1 percent of immigrants receiving their landed status prior to 1991 resided abroad in 1991. Most of these individuals likely misreported their place of residence on May 14, 1991 (the reference date used within the census to measure usual place of residence five years prior). Unlike the U.S., this is therefore a much more rigorous definition of the year of arrival, avoiding many of the shortfalls and problems of the "come to stay" question found in the U.S. census (Ellis and Wright 1998).
} 
place of birth, identifying immigrants from Asia, Europe, the Americas ${ }^{2}$ (Central America, South America and Caribbean origins), and "Rest of World" (ROW). Comparisons are also made to the native-born Canadian population aged five and over, where appropriate.

\section{Period Measures of Migration and Mobility}

Table 1 reports mobility and migration measures for the foreign-born population aged five and over between 1981 and 1986, 1986 and 1991, and 1991 and 1996, enabling two general conclusions to be drawn. First, local moves account for the largest proportion of all moves, with interprovincial migrations being the least likely. Second, the incidence of overall mobility varies widely by origin, being highest amongst those born in Asia or the Americas. Between 1986 and 1991, over 40 percent changed their place of usual residence, and greater than 50 percent changed their place of residence in both 1981-86 and 1991-96. In contrast, mobility rates were lower among European origins, with somewhat greater than 30 percent changing residence in each of the three census intervals. These differences also tend to persist at other geographic scales. While neither of these conclusions is hardly surprising, the diversity of rates across the origin groups is striking.

TABLE 1

Mobility and Migration Rates (\%) Among the Foreign-Born Aged 5+: 1981-86, 1986-91 and 1991-96

\begin{tabular}{lrrrrr}
\hline & European & Asian & American & ROW & Total \\
\hline 1991-96 & & & & & \\
Overall & 30.5 & 46.0 & 46.7 & 45.9 & 37.7 \\
Movers & 18.1 & 31.7 & 30.6 & 29.5 & 24.1 \\
Different CSD & 3.5 & 5.0 & 5.4 & 5.3 & 4.3 \\
Different CD & 6.5 & 6.0 & 7.9 & 6.7 & 6.6 \\
Interprovincial & 2.3 & 3.3 & 2.9 & 4.4 & 2.8 \\
1986-91 & & & & & \\
Overall & 33.8 & 52.2 & 52.9 & 46.8 & 40.1 \\
Movers & 18.6 & 33.4 & 32.2 & 25.5 & 23.1 \\
Different CSD & 4.4 & 6.4 & 6.3 & 5.7 & 5.0 \\
Different CD & 8.2 & 8.3 & 11.4 & 10.3 & 8.7 \\
Interprovincial & 2.7 & 4.4 & 2.9 & 5.3 & 3.3 \\
& & & & & \\
1981-86 & & & & 43.5 & 38.8 \\
Overall & 33.5 & 51.0 & 54.5 & 25.0 & 24.8 \\
Movers & 20.8 & 35.0 & 39.2 & 4.5 & 3.6 \\
Different CSD & 3.2 & 4.1 & 5.0 & 8.6 & 7.1 \\
Different CD & 6.8 & 7.2 & 7.2 & 5.4 & 3.4 \\
Interprovincial & 2.8 & 4.6 & 3.2 & & \\
\hline
\end{tabular}

Source: Derived from 1986, 1991, and 1996 Statistics Canada PUMF.

Note: $C D=$ Census Division; $C S D=$ Census Sub Division.

${ }^{2}$ Since the purpose of this paper is to discuss migration measures, aggregate measures of origin will suffice for the discussion. Moreover, definitions of origin are limited within the Canadian census. "American" or "Americas" will be used in this paper to denote immigrants from Central America, South America, and the Caribbean. Immigrants from the U.S. are placed in the ROW category since available evidence would suggest that Hispanic and Latin American immigrants behave differently from U.S. immigrants. 
Given the evidence of Table 1, it may be tempting to search for temporal variations in migration propensities. The period rates suggest, for example, that mobility and migration rates declined over the 1981-96 period, particularly between 1986-91 and 1991-96. Yet, to interpret and assign conclusions relating to changes in migration behavior across the three census intervals would be incorrect owing to compositional effects. In effect, these period rates are "snap-shots" of the migration system at particular points in time. Importantly, the foreign-born who are included in each of these samples were not the same group of individuals in 1986, 1991, and 1996, with two sources of biases being especially important.

First, between 1986 and 1996, new immigrant arrivals joined the existing foreign-born population. Since migration rates tend to be elevated among the recently arrived, the addition of new arrivals will tend to increase migration and mobility measures (Newbold 1999). High mobility shortly after arrival in the host country is associated with the adaptation to the new environment and linked with changes in locational preferences, employment opportunities, or housing (Newbold 1999). Moreover, if the relative size of specific national or ethnic groups within the arrival cohorts varies (such as the decreasing number of European arrivals and the corresponding increase in Asian immigrants since the 1960s), rates of movement may be altered. Groups that have benefited from recent and large-scale immigration into their communities would, ceteris paribus, have elevated migration propensities.

Second, variations in mobility and migration rates are associated with differences in the age structure of the population and duration of residence within Canada. Both effects work simultaneously, with migration and mobility propensities declining with increasing duration of residence. Differences in the age structure of the foreign-born are important since the propensity to migrate is highest among young adults and declines with age. In 1996, the average age of immigrants who arrived prior to 1960 was 63.9 years, which compares with the average age of 36.2 years among post-1981 arrivals and an average age within the native-born Canadian population of 36.1 years, meaning earlier arrivals will have lower migration rates relative to more recent arrivals. Although these effects are interrelated since age itself increases with increasing duration of residence, period of residency nevertheless exerts an independent impact upon migration propensities. Disaggregation by age and period of arrival demonstrates the effect of length of residency upon overall mobility within the foreign-born population (see Figure 1). At all spatial scales, the most recent arrivals were more likely to migrate than their like-aged counterparts who arrived earlier, with the pattern observed even amongst the elderly. Rates generally decrease with increasing duration of residence, converging toward those of the native-born. It is apparent that the adjustment and learning process affects all age groups, but the decline in mobility is most pronounced and the rate of convergence towards the profile of the nativeborn is the slowest at older ages. 


\section{FIGURE 1}

Overall Mobility by Age and Arrival Period, 1991-96

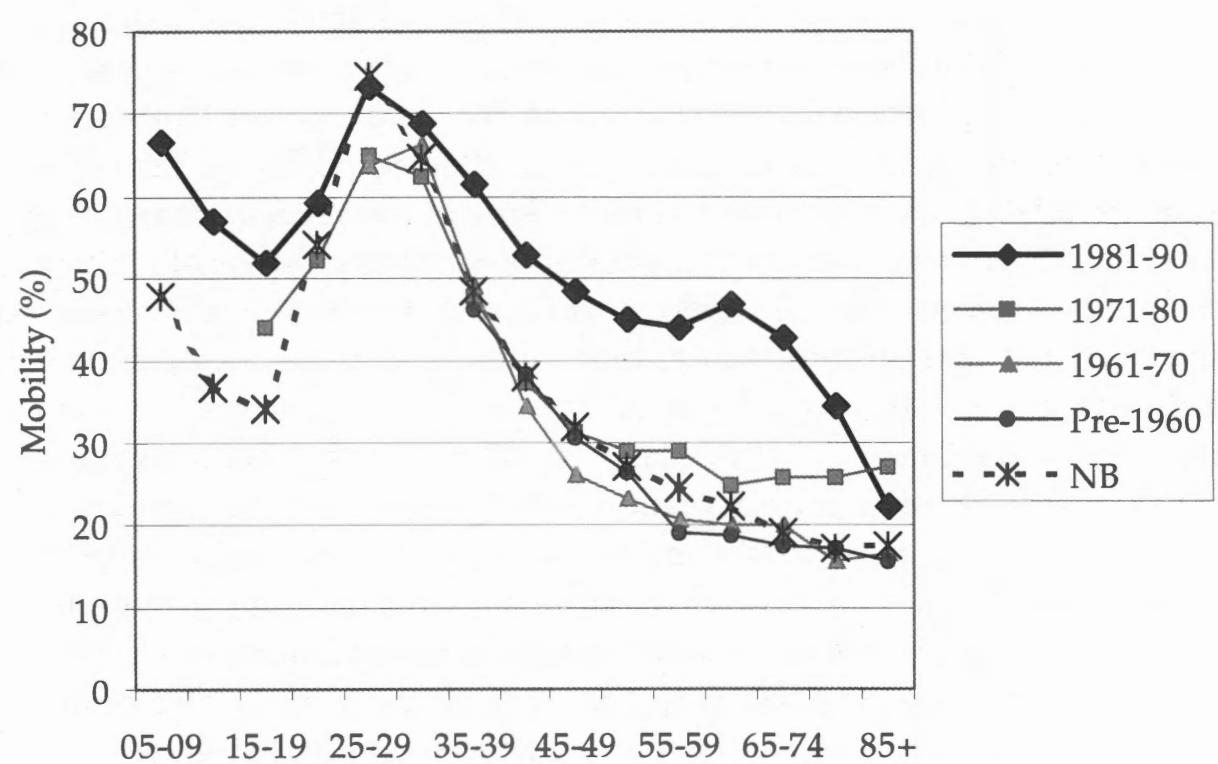

Age in 1996

Individual origins, however, may not follow the patterns shown in Figure 1 , since the effects of age and duration of residence are also bound to changes in immigration policy in the postwar decades. Prior to immigration reform, the majority of immigrants arriving in Canada sourced from either U.S. or European origins. After reforms in the 1960s that removed origin biases and promoted the points system, Asian origins dominated and levels of endowed human capital among more recent arrivals have increased, making it important to recognize that the composition of arrival cohorts has changed dramatically. In other words, comparison of the age schedules of specific origin groups while controlling for period of arrival would likely yield different structures.

\section{Double Cohort Measures of Migration and Mobility}

Correcting for the above biases means defining sample populations with respect to age and period of arrival in order to minimize the linked effects of age and residency. Disaggregating by four origin areas (Europe, Asia, Americas, and ROW) and refining the age distribution to those aged 45-59 in 1996, the results in panels 1 and 2 of Table 2 (which do not disaggregate by arrival period) are consistent with expectations derived from the literature, with the patterns echoing those found in Table 1.

Panel 3 in Table 2 and Figures 2a-e further disaggregate by arrival cohort, with mobility and migration rates reported for the 1991-96 interval (similar rates can be constructed for the previous census intervals). Disaggregation by period of arrival demonstrates the difficulty of arriving at appropriate measures of migration. 
Mobility and migration rates are highest amongst recent arrivals, with the period immediately after arrival likely reflecting adjustment, sparse ties to place, and new information relating to other options across space (Newbold 1999). In addition to higher mobility rates relative to other origin groups, 1991-96 rates among recent immigrants from the Americas ( 52.2 percent) were nearly twice those of the overall mobility rate (28.9 percent) during the same period. Among immigrants arriving between 1981-90, overall mobility levels ranged from 42.2 percent among Europeans to 52.2 percent among immigrants from the Americas. Likewise, interprovincial migration rates ranged from 3.5 percent among ROW origins to 2.6 percent among immigrants from Europe. Although rates generally decreased with increasing duration of residence, elevated rates among those with the longest period of residency within Canada (pre-1960 arrivals) were observed in several cases. This may, in part, represent uncaptured age effects. Although samples were defined to capture those aged 45-59 in 1996, earlier arrival cohorts will still have an older mean age, so that the rates may capture increases in migration propensities associated with retirement. Alternatively, the increase in rates may be a statistical artifact, although its exact explanation is unclear.

TABLE 2

Mobility and Migration Rates (\%) by Cohort and Origin, 1991-96: Aged 45-59 in 1996

\begin{tabular}{cccccc}
\hline & Overall & Movers & Different CSD & Different CD & Interprov. \\
\hline (1) All Cohorts/Origins & 28.9 & 18.4 & 3.5 & 5.1 & 1.9 \\
(2) All Cohorts by Origin: & & & & & \\
Europe & 26.2 & 15.6 & 3.2 & 5.7 & 1.8 \\
Asia & 32.4 & 22.6 & 3.9 & 3.8 & 2.1 \\
Americas & 34.2 & 23.1 & 4.1 & 4.9 & 2.1 \\
ROW & 32.0 & 21.6 & 3.3 & 4.5 & 2.6
\end{tabular}

(3) By Origin and Cohort (1991-96):

\begin{tabular}{|c|c|c|c|c|c|c|}
\hline Europe & Pre-1960 & 25.0 & 13.9 & 3.1 & 6.2 & 1.8 \\
\hline & $1961-70$ & 22.8 & 13.3 & 3.0 & 5.0 & 1.5 \\
\hline & $1971-80$ & 29.6 & 18.8 & 3.5 & 5.7 & 1.6 \\
\hline & $1981-90$ & 42.2 & 29.8 & 3.8 & 6.7 & 2.6 \\
\hline Asia & Pre-1960 & 25.4 & 17.3 & 4.1 & 3.1 & 1.0 \\
\hline & $1961-70$ & 22.8 & 14.6 & 3.7 & 3.4 & 1.1 \\
\hline & $1971-80$ & 27.8 & 19.3 & 3.1 & 3.9 & 1.5 \\
\hline & $1981-90$ & 46.3 & 33.4 & 5.2 & 4.3 & 3.6 \\
\hline Americas & Pre-1960 & 32.0 & 20.2 & 4.8 & 5.7 & 2.0 \\
\hline & $1961-70$ & 26.8 & 17.8 & 3.2 & 4.8 & 1.2 \\
\hline & $1971-80$ & 33.8 & 22.4 & 4.2 & 5.0 & 2.3 \\
\hline & $1981-90$ & 52.2 & 38.3 & 5.6 & 5.2 & 3.1 \\
\hline ROW & Pre-1960 & 36.7 & 16.7 & 1.7 & 11.7 & 6.7 \\
\hline & $1961-70$ & 21.3 & 11.6 & 2.8 & 5.0 & 1.9 \\
\hline & $1971-80$ & 30.4 & 21.4 & 3.6 & 3.6 & 1.8 \\
\hline & $1981-90$ & 51.4 & 38.7 & 4.2 & 4.9 & 3.5 \\
\hline
\end{tabular}

Source: Derived from 1986, 1991, and 1996 Statistics Canada PUMF.

Note: CSD = Census Sub Division; $C D=$ Census Division; Interprov. = Interprovincial. 
FIGURE 2a-e

Mobility and Migration Rates (\%) by Cohort and Origin, 1991-96: Aged 45-59 in 1996

a. Overall Mobility

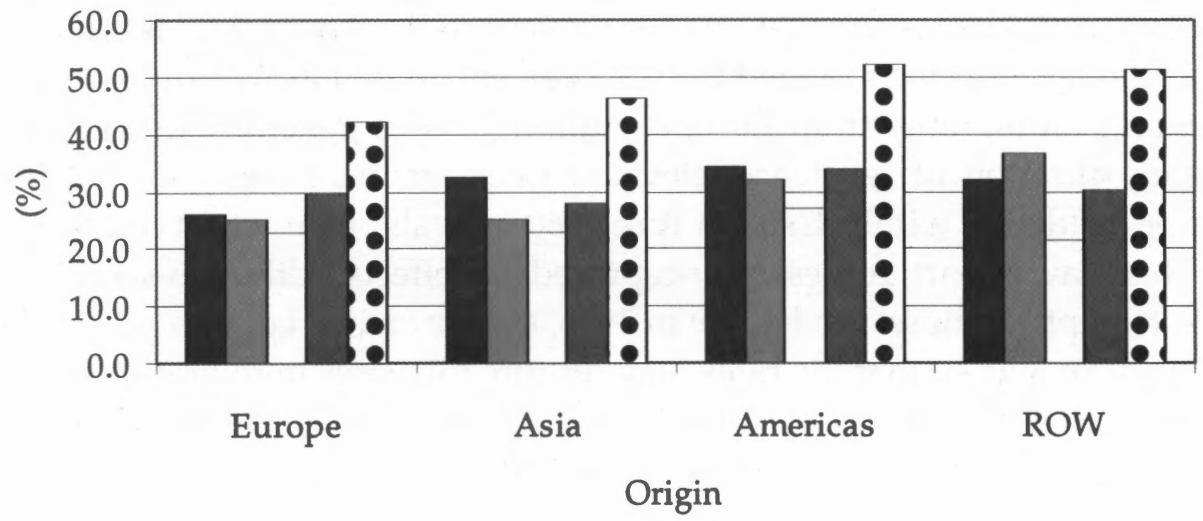

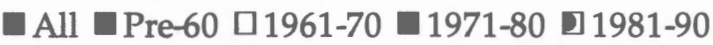

b. Movers

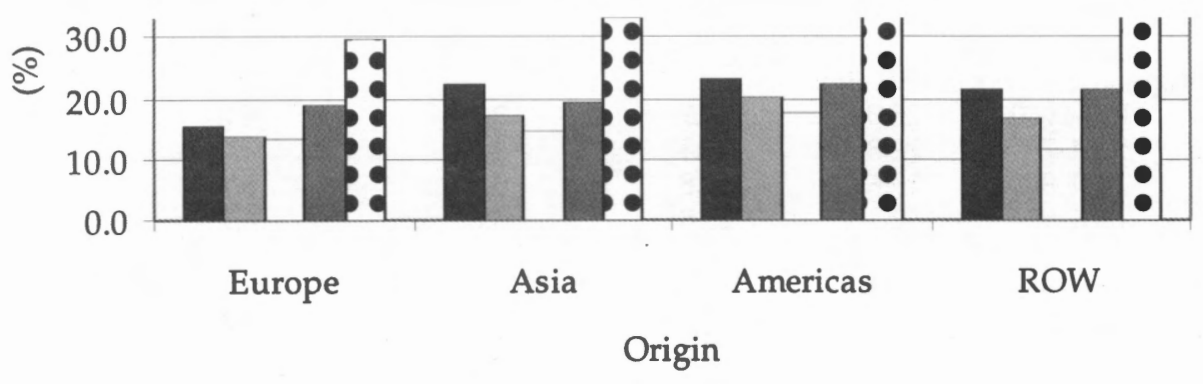

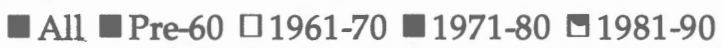


c. Different CSD

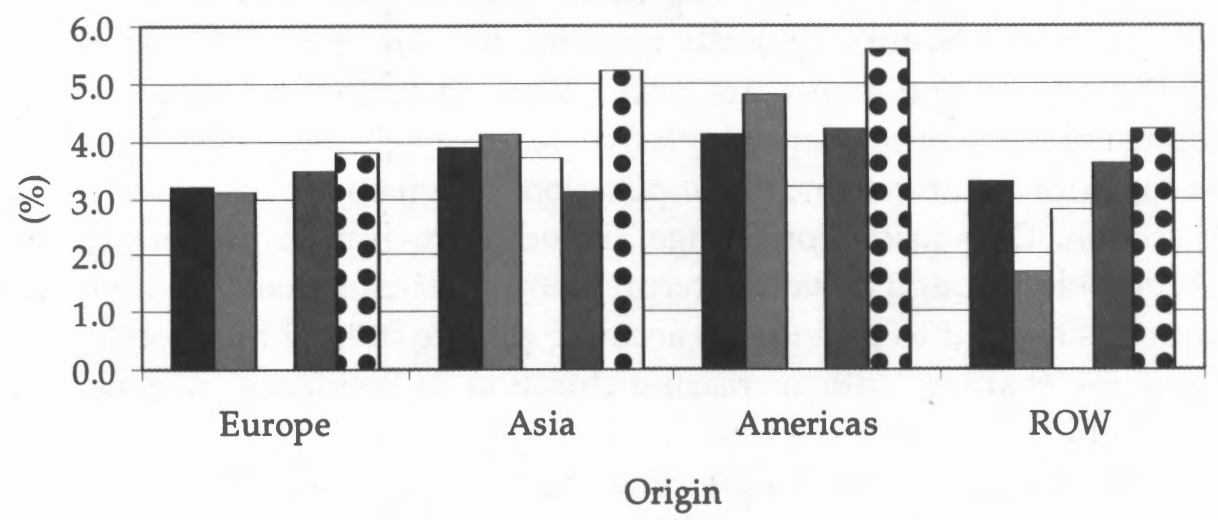

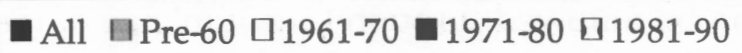

d. Different CD

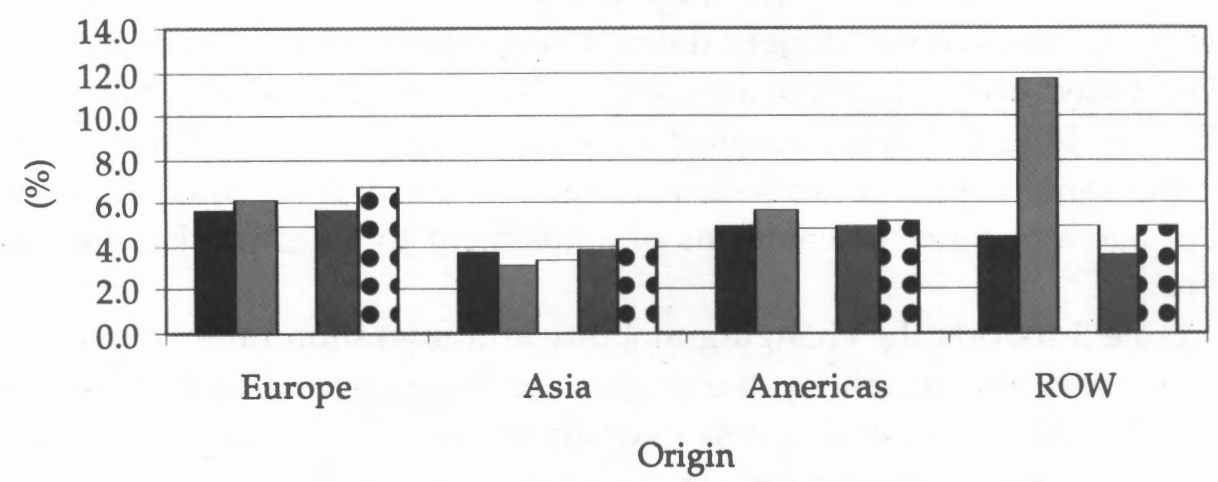

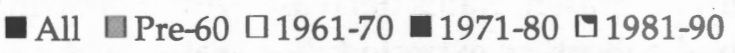

e. Interprovincial

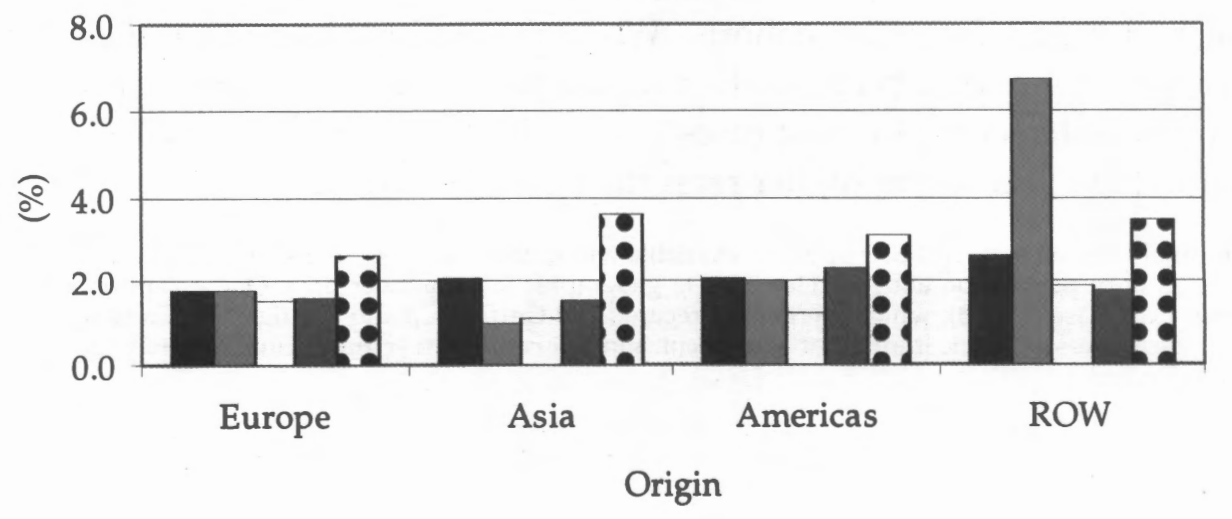


This still, however, provides only a "static" interpretation of migration measures. That is, most census files provide only limited information regarding previous residential history, typically referring to usual place of residence at the time of the census and five-years prior. More recently, Statistics Canada has recorded usual place of residence both five years prior to the census date as well as one year prior to the census, the implications of which are discussed in the following section. Dimensions of change, including migration propensity, are not truly observable through a static interpretation of census material. Longitudinal data, which is needed to provide an accurate picture of how the mobility of particular groups changes with increasing duration of residence, is generally not available within Canada or the U.S. ${ }^{3}$

In the absence of true longitudinal data, one option is to link consecutive census files, creating a "pseudo-panel" (Borjas 1985; Borjas and Bratsberg 1996). In effect, cohorts can be followed through time. Linkage of the 1986, 1991, and 1996 census files allows immigrant cohorts to be defined, providing greater control and comparability of the immigrant population and its characteristics. Since it is likely that immigrants will differ in their migration and redistribution tendencies across a number of dimensions, "doubly defined" cohorts (Myers and Lee 1996) were identified based upon period of arrival (pre-1960, 1961-70, 1971-80, 1981-90) and aged 35-49 in 1986. Cohorts were then allowed to "age" over the census intervals so that the same cohort of arrivals was aged 45-59 in 1996, thus allowing the effects of age and other mechanisms of adjustment to be controlled and traced over time.

Table 3 reports the changing mobility and migration rates over the three census intervals. For simplicity, the origins are aggregated, although the results noted in Table 3 are consistent across all origin groups. Only after period of arrival and age have been controlled for can conclusions regarding the temporal evolution of the system be drawn. Rates decrease with increasing duration of residence within each arrival cohort, as expected. For example, the overall mobility rate for 1961-70 arrivals was 36.7 percent during 1981-86, a rate that dropped to 32.8 percent by 1986-91, and 23.3 percent by 1991-96. Similar effects are observed at other spatial scales and for other cohorts. While generally lower rates are observed among those who have been resident within the country for a longer period, it is not a universal decline. In most cases (and including by origin), pre-1960 arrivals tended to have somewhat higher rates than 1961-70 arrivals.

\footnotetext{
${ }^{3}$ Longitudinal files, such as the PSID or NLSY available within the U.S. for example, typically lack a sufficiently large foreign-born population and/or references to geographic location over time. One exception is Canada's Immigrant Data Base (IMDB), which merges tax records and Citizenship and Immigration Canada (CIC) data, allowing researchers to track immigrant settlement and adjustment over time. Unfortunately, access to this resource is limited.
} 
TABLE 3

Mobility and Migration Rates (\%) by Cohort, 1986, 1991, and 1996: Aged 45-59 in 1996

\begin{tabular}{|c|c|c|c|c|c|}
\hline & Overall & Movers & Different CSD & Different CD & Interprov. \\
\hline \multicolumn{6}{|c|}{ 1981-90 Arrivals } \\
\hline 1991 & 56.1 & 34.9 & 6.0 & 10.2 & 5.0 \\
\hline 1996 & 46.5 & 33.4 & 4.8 & 5.1 & 3.2 \\
\hline \multicolumn{6}{|c|}{ 1971-80 Arrivals } \\
\hline 1986 & 53.1 & 35.5 & 4.5 & 8.0 & 4.8 \\
\hline 1991 & 44.8 & 26.7 & 5.4 & 9.2 & 3.5 \\
\hline 1996 & 29.8 & 19.8 & 3.5 & 4.7 & 1.8 \\
\hline \multicolumn{6}{|c|}{ 1961-70 Arrivals } \\
\hline 1986 & 36.7 & 23.3 & 3.7 & 6.7 & 3.0 \\
\hline 1991 & 32.8 & 18.9 & 4.0 & 7.5 & 2.4 \\
\hline 1996 & 23.3 & 14.0 & 3.1 & 4.7 & 1.5 \\
\hline \multicolumn{6}{|c|}{ Pre-1960 Arrivals } \\
\hline 1986 & 38.1 & 22.5 & 4.0 & 8.2 & 3.4 \\
\hline 1991 & 33.3 & 17.7 & 4.8 & 8.0 & 2.8 \\
\hline 1996 & 25.4 & 14.2 & 3.2 & 6.0 & 1.9 \\
\hline
\end{tabular}

Source: Derived from 1986, 1991, and 1996 Statistics Canada PUMF

Note: $\mathrm{CSD}=$ Census Sub Division; $\mathrm{CD}$ = Census Division; Interprov. = Interprovincial.

\section{Implications of Alternate Cohort Definitions}

Such examples of the geographic mobility of the immigrant population underscore the diversity of the system. Immigrant origins and age/arrival cohorts display an astonishingly broad diversity of movement, which is hidden in more aggregate analyses that fail to appropriately control for period of arrival and age. Beyond the more refined measures of migration and mobility, what are the implications with respect to modeling migration as one moves from "all origins/all cohorts" to "doubly defined" cohorts? Using the departure decision (move/stay) of Europeans as an example, Table 4 reports the logistic results for three sample populations: all cohorts, aged 5 plus; all cohorts, aged 45-59 in 1996; and 1981-90 arrivals aged 45-59 in 1996. Models for overall mobility (all moves, regardless of distance) and interprovincial migration are illustrated. ${ }^{4}$ Explanatory variables used within the model were selected based upon previous results along with migration and immigration theory (see, for example, Newbold 1996). All the variables were "forced" into the model to ensure equivalent models, a criterion necessary for the testing of coefficients across the sample populations.

Although it is clear that there is some variation across the sample groups, the outmigration propensities of foreign-born Europeans behaved as would be hypothesized. For example, outmigration propensities were reduced by higher per capita incomes and greater employment growth, and increased by higher

${ }^{4}$ Analysis of departure choice at other spatial scales revealed similar effects. 
population shares and cold environments. Personal attributes also affected outmigration propensities, with those who owned their own home and females less likely to depart in general. Conversely, the highly educated (BA or better) and professionals were more likely to depart, reflecting their potentially greater opportunities across the country.

TABLE 4

Effects of the Overall Mobility and Interprovincial Migration Departure Choice Models, 1991-96: Europeans by Arrival and Age Cohort

\begin{tabular}{|c|c|c|c|c|c|c|c|c|}
\hline & \multicolumn{2}{|c|}{$\begin{array}{l}\text { All Cohorts } \\
\text { Aged 5+ } \\
\text { (A) }\end{array}$} & \multicolumn{2}{|c|}{$\begin{array}{l}\text { All Cohorts } \\
\text { Aged 45-59 } \\
\text { (B) }\end{array}$} & \multicolumn{2}{|c|}{$\begin{array}{l}1981-90 \text { Cohort } \\
\text { Aged 45-59 } \\
\text { (C) }\end{array}$} & \multicolumn{2}{|c|}{$\begin{array}{l}\text { Asymptotic } \\
t \text {-test of } \\
\text { Coefficients }\end{array}$} \\
\hline & Coeff. & $t$ & Coeff. & $t$ & Coeff. & $t$ & $\mathrm{~A}: \mathrm{C}$ & $\mathrm{B}: \mathrm{C}$ \\
\hline \multicolumn{9}{|l|}{ Interprovincial: } \\
\hline Constant & $-17.70^{*}$ & -19.3 & $-18.45^{*}$ & -11.5 & $-28.64^{*}$ & -3.2 & -1.2 & -1.1 \\
\hline Per Cap. Income & $-0.02 *$ & 9.3 & $-0.23^{*}$ & 5.6 & $-0.38^{*}$ & 2.5 & 1.2 & 1.0 \\
\hline Employ. Growth & $-0.05^{*}$ & -16.5 & $-0.46^{*}$ & -7.5 & $-0.36^{*}$ & -2.0 & 0.7 & 0.5 \\
\hline Population & $0.04^{*}$ & 8.6 & $0.03^{*}$ & 3.3 & 0.00 & 0.0 & -1.3 & -1.0 \\
\hline Coldness & $2.46^{*}$ & 15.1 & $2.38^{*}$ & 8.5 & $4.20^{*}$ & 2.6 & 1.1 & 1.1 \\
\hline Sex: Female & -0.11 & -1.8 & $-0.22^{*}$ & -2.0 & -0.42 & -1.1 & -0.8 & -0.5 \\
\hline Tenure: Own & $-1.07^{*}$ & -17.5 & $-0.59^{*}$ & -4.4 & $0.31^{*}$ & 2.4 & $9.8^{*}$ & $4.8^{*}$ \\
\hline DSW & $-0.28^{*}$ & -3.8 & 0.25 & 1.8 & 0.25 & 0.5 & 1.1 & 0.0 \\
\hline High Ed. & $0.66^{*}$ & 8.3 & $0.31^{*}$ & 2.0 & 0.37 & 0.8 & -0.6 & 0.1 \\
\hline Naturalized & 0.06 & 0.7 & 0.13 & 0.8 & -0.19 & -0.5 & -0.6 & -0.7 \\
\hline Professional & $0.27^{*}$ & 3.5 & 0.20 & 1.4 & -0.17 & -0.4 & -0.9 & -0.7 \\
\hline N (unweighted) & 56,855 & & 19,102 & & 1,270 & & & \\
\hline Rho-squared & 0.13 & & 0.11 & & 0.11 & & & \\
\hline \multicolumn{9}{|l|}{ Overall Mobility: } \\
\hline Constant & 0.72 & 1.7 & 0.54 & 0.7 & 3.58 & 1.3 & 1.0 & 1.0 \\
\hline Per Cap. Income & 0.00 & 0.0 & 0.00 & 0.0 & -0.01 & -0.2 & -0.2 & -0.2 \\
\hline Employ. Growth & $-0.10^{*}$ & -6.8 & $-0.12^{*}$ & -4.4 & -0.01 & -0.1 & 1.0 & 1.2 \\
\hline Population & $0.02 *$ & 10.4 & $0.02^{*}$ & 6.8 & 0.02 & 1.4 & -0.3 & -0.6 \\
\hline Coldness & -0.14 & -1.8 & -0.20 & -1.4 & -0.73 & -1.4 & -1.2 & -1.0 \\
\hline Sex: Female & $-0.09^{*}$ & -4.8 & $-0.19^{*}$ & -5.3 & $-0.42 *$ & -3.4 & $-2.6^{*}$ & -1.8 \\
\hline Tenure: Own & $-1.24^{*}$ & -55.1 & $-1.10^{*}$ & -24.6 & $-0.74^{*}$ & -5.7 & $3.7^{*}$ & $2.6^{*}$ \\
\hline DSW & $0.16^{*}$ & 6.6 & $0.87^{*}$ & 19.9 & $0.51^{*}$ & 3.2 & $2.2^{*}$ & $-2.2^{*}$ \\
\hline High Ed. & $0.35^{*}$ & 10.8 & $0.13^{*}$ & 2.4 & 0.20 & 1.3 & -0.9 & 0.4 \\
\hline Naturalized & $-0.29 *$ & -10.5 & -0.09 & -1.8 & 0.02 & 0.2 & $2.1^{*}$ & 0.7 \\
\hline Professional & $0.30^{*}$ & 10.3 & 0.01 & 0.1 & $-0.39 *$ & -2.3 & $-4.0^{*}$ & $-2.3^{*}$ \\
\hline $\mathrm{N}$ (unweighted) & 56,855 & & 19,102 & & 1,270 & & & \\
\hline Rho-squared & 0.07 & & 0.08 & & 0.05 & & & \\
\hline
\end{tabular}

*Significant at $\mathrm{p}<0.05$.

DSW = Divorced, Separated, Widowed.

Of particular interest is whether these immigrant samples respond differentially to the determinants of migration. Given similar models, the coefficients and their variances can be compared using the asymptotic $t$-test for equality of individual coefficients (Ben-Akiva and Lerman 1985), with the $t$-test results reported in the final two columns of Table 4. Analysis reveals two general conclusions. First, while the results indicate that the cohorts do respond differentially to the determinants of migration, personal attributes were the most sensitive to changing sample definitions, while the effects of macroeconomic factors (i.e., 
income, employment growth) were consistent across the three samples. For example, the most recent arrivals (1981-90) who owned their own home were significantly more likely to make an interprovincial migration than either of the other sample immigrant groups. Additional differences were also observed with respect to overall mobility, with sample cohorts differing by tenure status, marital status, sex, occupation, and naturalization. Consequently, in addition to differential measure of spatial adjustment found earlier, specification of the immigrant sample impacts upon determinants of migration. This may lead to the estimation of incorrect signs and/or incorrect assessments of the probability to migrate, an issue that has deeper implications with respect to the assimilation and adjustment debate. That is, the improper specification of immigrant samples may lead to conflicting results. Second, although not shown on Table 4, such differences were not observed between those cohorts that arrived earlier (i.e., 1971-80 arrivals aged 45-59) and the other sample groups (all cohorts/all ages and all cohorts, aged 45-59). In both cases, this may reflect the generally elevated mobility levels of the most recent arrivals, such that their motivation to relocate differs in substantive ways from earlier, but similarly defined, groups.

\section{RETURN AND ONWARD INTERPROVINCIAL MIGRATION}

The second part of this paper returns to a more "static," or traditional, interpretation of migration events through its reliance upon a single census interval to capture salient issues related to the timing of migration. This is, by far, the framework most commonly used within migration analyses, whether focusing upon the native- or foreign-born population, owing to the ease of data utilization and definition of migration events within most census files.

When deriving measures of migration, whether they are rates, flows, streams, or other empirical measures, such as net migration or migration efficiency, the length of the migration interval impacts upon the number of migrants captured. Too long an interval risks missing migrants. Most developed countries, including the U.S., Canada, and Australia, have gathered migration data based upon place of usual residence five years before the census. Although data based upon a five-year interval provide a clear picture of the spatial impacts of migration, it also typically undercounts migration events (Morrison 1971; Newbold and Bell 2001). That is, an individual residing in province $A$ in 1991 may migrate between 1991 and 1996, but return to his or her 1991 province of residence by census day in 1996. In this respect, the individual's migration has been "missed." Conversely, too short an interval may add "noise" to the overall system by capturing short-term perturbations to the system and nonpermanent relocations, including extended vacations, short-term transfers associated with employment, and circulation.

Use of one-year migration data provides an alternate method to explore questions relating to migration as a repetitive event, including the analysis of return migration. Statistics Canada has recently (since 1991) collected data on 
place of residence both one and five years prior to the enumeration date. Often overlooked, this data can provide migration researchers with a number of advantages, including shorter intervals over which migration is measured (one and four years) and improved measures of migration events through an alternative definition of return and onward migration. Demonstrating the selective nature of migration along with its demographic impacts, return and onward migration have been shown to be significant components of interregional migration flows. These findings have typically been based upon lifetime return migrations, with individuals returning to their place of birth. There are, however, two problems with this definition of "lifetime" return migration. First, individuals may have engaged in several migrations prior to the census, with the scope of these moves varying with age. Birthplace may, in fact, be a poor proxy for the concept of a "home" region, which characterizes a region or place of familiarity (Newbold and Bell 2001). Second, and more importantly in the context of this paper, studies of return and onward migration have been limited to the native-born population only, given the need to define a province of birth. Defining the place of residence at the start of the census interval as the "origin" and comparing that with the place of residence four and five years later provides an alternate way to define return and onward migration. The introduction of one- and five-year residency data offers two additional advantages. First, the level of spatial detail within the Canadian census allows the identification of a return to a previous residence. Typically, most studies of return migration have been limited to returns to a province or state of birth (i.e., Long 1988; Newbold and Liaw 1990, 1994). Second, the short time over which migration is measured means that personal attributes such as education or marital status are less likely to have changed, and can therefore be more reliably linked to spatial choice decisions.

Consequently, the use of fixed interval data improves (or at least offers an alternative to) the ability to inquire into migrations made by the foreign-born. Using the 1996 census, it is possible to compare place of residence at three fixed points in time, including at the time of the census, one year prior to the census (1995) and five years prior to the census (1991). Migrants and migrations are therefore defined by reference to changes of usual place of residence over the 1991-95 and 1995-96 intervals. To simplify the analysis, individuals aged less than five at the time of the census, along with those who were outside of Canada or did not report a place of residence at any of the three points in time, were excluded. This allows five groups to be identified (Bell 1996):

1. People who did not migrate between 1991 and 1996 (those whose province of residence was the same at all three points in time);

2. People who made an interprovincial migration between 1991 and 1995 but not between 1995 and 1996;

3. People whose province of residence was unchanged between 1991 and 1995 but who migrated between 1995 and 1996; 
4. People who migrated between 1991 and 1995 and who returned to their previous (1991) province of residence by 1996; and

5. People who made an interprovincial migration between 1991 and 1995 and who migrated again to a different province between 1995 and 1996.

The fourth group can be defined as return migrants and the fifth as "onward" migrants, resulting when individuals make an additional migration to a location that differs from their 1991 and 1995 province of residence. Return migrants were further disaggregated to distinguish between those returning to their original (start of census) dwelling and those who returned elsewhere in their province of origin. Results presented in Table 5 are reported for both the foreignborn and native-born. ${ }^{5}$

\section{TABLE 5}

Interprovincial Return and Onward Migration Among the Foreign-Born and Native-Born, Canada: 1991-95, 1995-96

\begin{tabular}{|c|c|c|}
\hline Type of Migration & Foreign-Born & Native-Born \\
\hline Did not migrate & $3,759,624$ & $16,613,064$ \\
\hline Returned to same dwelling & 1,764 & 13,932 \\
\hline Returned to same province & 4,032 & 46,296 \\
\hline Total returned & 5,796 & 60,228 \\
\hline Migrated onward & 2,016 & 17,532 \\
\hline Total multiple & 7,812 & 77,760 \\
\hline Migrated $1995-96$ only & 18,936 & 106,812 \\
\hline All 1995-96 migrations & 26,748 & 184,572 \\
\hline Migrated 1991-95 only & 85,320 & 465,804 \\
\hline All 1995-96 migrations & 93,132 & 543,564 \\
\hline Total migrations & 119,880 & 728,136 \\
\hline Total migrants & 112,068 & 650,376 \\
\hline Recorded migrations 1991-96 & 106,272 & 590,148 \\
\hline \multicolumn{3}{|l|}{ Percent of total 1991-95 migrants: } \\
\hline Returned to same dwelling & 1.9 & 2.6 \\
\hline Returned to same province & 4.3 & 8.5 \\
\hline Total returned & 6.2 & 11.1 \\
\hline Migrated onward & 2.2 & 3.2 \\
\hline Total multiple & 8.4 & 14.3 \\
\hline \multicolumn{3}{|c|}{ Percent of total 1995-96 migrants: } \\
\hline Returned to same dwelling & 6.6 & 7.5 \\
\hline Returned to same province & 15.1 & 25.1 \\
\hline Total returned & 21.7 & 32.6 \\
\hline Migrated onward & 7.5 & 9.5 \\
\hline Total multiple & 29.2 & 42.1 \\
\hline Total population & $3,871,692$ & $17,263,980$ \\
\hline
\end{tabular}

${ }^{5}$ Foreign-born numbers do not allow disaggregation by origin or period of arrival if the detail of return migration is to be maintained. Likewise, there are insufficient numbers within the PUMF for reliable multivariate analysis of return and onward migrations among the foreign-born. Native-born includes those aged five and over in 1996 who were born in Canada and resident in 1991, 1995, and 1996. 
Among the foreign-born, 119,880 migrations were recorded between 1991 and 1996. As these migrations were made by 112,068 migrants (obtained by subtracting the total number of migrants from the number of return and onward migrants), it is apparent that some individuals migrated more than once during the census interval. Of these, 76.1 percent migrated during 1991-95 and16.9 percent migrated during $1995-96$. The remaining 7 percent $(7,812)$ migrated in both the 1991-95 and 1995-96 intervals. Among the native-born, a total of 650,376 interprovincial migrants aged five and over were identified, with 71.6 percent migrating in the first interval, 16.4 percent migrating in the second, and 12.0 percent making an interprovincial migration in both intervals.

The role of repeat migrations is made more apparent when viewed relative to the number migrating in either the first (1991-95) or second (1995-96) interval. By definition, repeat migrants must have changed their province of residence between 1991 and 1995. This means that the total number of foreign-born migrants in the first interval $(85,320)$ defines the "at-risk" population for making either a return or onward migration. Compared to this base, repeat migrants represent 8.4 percent of migrations during the 1991-95 interval, and an even larger share (29.2 percent) among those who migrated between 1995-96. Among the native-born, repeat migrations represented 14.3 percent of moves within the 1991-95 interval and 42.1 percent of migrations between 1995 and 1996, making them more likely to engage in both return and onward migrations than the foreign-born. In fact, the native-born were consistently and significantly more likely to engage in either a return or onward migration, including returns to the 1991 origin dwelling.

Table 5 also demonstrates the one- and five-year problem in migration analysis, which arises from the observation that the number of five-year migrations is much less than the number of migrations recorded in a single year (Kitsul and Philipov 1981; Rogerson 1990). For example, the 26,748 migrations recorded between 1995 and 1996 among the foreign-born would translate, if directly extrapolated, to 133,740 migrations over five years. This means that 27,468 (20.5 percent) of migrations were "lost" over the five-year period. Such differences are, of course, to be expected, with the disparity between lifetime and fixed interval measures accounting for a portion of this difference. Multiplication by five implicitly assumes that a different set of people migrate each year, while failing to account for population heterogeneity and chronic mobility (Rogerson 1990).

\section{CONCLUSIONS}

This paper has explored the effects of interval length and composition on migration measures. Invariably, the length of the migration interval has clear and well-known effects, with the number of counted migrations inversely related to space and directly related to the length of the migration interval. Direct extrapolation of one-year flows to a five-year period overestimates the number of migrations recorded within the five-year interval. Clearly, the length of the time interval used will influence the results and their interpretation, which speaks to the problem of reconciling results when flow data having different intervals are employed 
(Rogerson 1990). One-year data may represent and capture short-term changes within the system and migrant responses to those changes. They may also represent short-term effects within the system. Five-year data smooth these variations out. Ultimately, the use of migration measures based upon one- or five-year data should reflect the research questions at hand.

While this finding is not new, evaluations of one- and five-year migration indices provide additional insight into the migration process, including defining return and onward migrations, particularly when additional spatial detail is forthcoming from the data. Comparison of migration propensities between the foreignand native-born reveals subtleties not directly evidenced: the incidence of repeat migrations varies between groups, with the native-born being more likely to engage in either a return or onward migration.

Compositional effects, which reflect differences between arrival cohorts are, perhaps, more complicated. They capture effects such as the changing quality of immigrant arrivals, changes to immigration policy, new arrivals, etc., all of which will also obscure and confound migration indices. Consequently, composition effects require even greater attention than the interval effects noted above. The complexity and nonexclusive nature of these compositional effects complicates the construction of accurate measures of migration. Summary measures of migration are particularly problematic, since they fail to account for compositional effects that include age and period of arrival. Although these effects are interrelated, with age itself increasing as duration of residence increases, period of residence nevertheless exerts an independent impact upon migration propensities. In most cases, recent arrivals have the highest mobility rates regardless of age, which generally diminish and converge toward those of the native-born as length of residency increases.

The relevance of defining appropriate migration measures based upon period of arrival lies in their interpretation and use. This paper illustrated, for example, the variations in mobility and migration rates across sample immigrant populations. The implication of these variations in mobility, which also translate into differences with respect to migration decisions, is significant: how migration of the foreign-born is measured impacts the debate regarding their adaptation to a host society, a debate that social scientists are actively engaged in. As such, studies of the progression of immigrants from arrival onwards within the host society must be aware of these issues and use the appropriate methodology. That is, to gauge the adaptation of immigrants to a host society, immigrants should be defined via "doubly defined cohorts," referencing their period of arrival and age, in addition to the now-standard differentiation by origin.

\section{REFERENCES}

Beaujot, R. "Migration Trends and Policies in North America: The Case of Canada." Paper prepared for an OECD Conference in Mexico. Department of Sociology, University of Western Ontario, London, Ontario, 1998. . Population Change in Canada. Toronto: McCelland Stewart, 1991. 
Belanger, A., and A. Rogers. "The Internal Migration and Spatial Redistribution of the Foreign-Born in the United States: 1965-70 and 1975-80." International Migration Review 4 (1992), 1242-1369.

Bell, M. "Repeat and Return Migration." In P.W. Newton and M. Bell (eds.) Population Shift: Mobility and Change in Australia, 147-164. Canberra: Australian Government Publishing Service, 1996.

Ben-Akiva, M., and S.R. Lerman. Discrete Choice Analysis: Theory and Applications to Travel Demand. Cambridge, MA: MIT Press, 1985.

Borjas, G.J. "Assimilation, Changes in Cohort Quality, and the Earnings of Immigrants." Journal of Labor Economics 3 (1985), 463-489.

Borjas, G.J., and B. Bratsberg. "Who Leaves? The Outmigration of the ForeignBorn." The Review of Economics and Statistics 78 (1996), 165-176.

Bourne, L.S. "Migration, Immigration and Social Sustainability: The Recent Toronto Experience in a Comparative Context." Joint Centre of Excellence for Research on Immigration and Settlement working paper, Toronto, 1999.

Bourne, L.S., and D.S. Ley. The Changing Social Geography of Canadian Cities. Montreal: McGill-Queen's University Press, 1993.

Ellis, M., and R.Wright. "When Immigrants are not Migrants: Counting Arrivals of the Foreign-Born Using the U.S. Census." International Migration Review 32 (1998), 127-144.

Fong, E., and R. Wilkes. "The Spatial Assimilation Model Re-Examined: An Assessment by Canadian Data." International Migration Review 33 (1999), 594-620.

Harvey, E.B., K. Reil, and B. Siu. "Changing Patterns of Immigrants and Socioeconomic Integration, 1986-1995, and their Policy and Program Implications." Joint Centre of Excellence for Research on Immigration and Settlement working paper, Toronto, 1999.

Kazemipur, A., and S.S. Halli. "The Colour of Poverty: A Study of the Poverty of Ethnic and Immigrant Groups in Canada." International Migration 38 (1999), 69-88.

Kitsul, P., and D. Philipov. "The One Year/Five Year Migration Problem." In A. Rogers (ed.) Advances in Multiregional Mathematical Demography, 1-34. Research Report 81-6. Laxenburg, Austria: International Institute for Applied Systems Analysis, 1981.

Kobayashi, A., E.G. Moore, and M. Rosenberg. "Healthy Immigrant Children: A Demographic and Geographic Analysis." Human Resources Development Canada, Working Paper W-98-20E, Ottawa, 1998.

Kobayashi, A., and L. Peake. "Urban Studies Research on Immigrants and Immigration in Canadian Cities." Paper prepared for Strategic Policy, Planning and Research and Metropolis Project, Citizenship and Immigration Canada, 1997.

Lieberson, S., and M.C. Waters. "The Location of Ethnic and Racial Groups in the United States." Sociological Forum 2 (1987), 780-810. 
Lo, L., and S. Wang. "Immigrants, Ethnic Economy and Integration: Case Study of Chinese in the Greater Toronto Area." Joint Centre of Excellence for Research on Immigration and Settlement working paper, Toronto, 1999.

Long, L. Migration and Residential Mobility in the United States. New York: Russell Sage Foundation, 1988.

Majury, N. "Signs of the Times: Kerrisdale, a Neighbourhood in Transition." Canadian Geographer 38 (1994), 265-270.

Morrison, P.A. "Chronic Movers and the Future Redistribution of Population." Demography 8 (1971), 171-184.

Myers, D., and S.W. Lee. "Immigration Cohorts and Residential Overcrowding in Southern California." Demography 33 (1996), 51-65.

Newbold, K.B. "Evolutionary Immigrant Settlement Patterns: Concepts and Evidence." In K. Pandit and S. Davies-Withers (eds.) Migration and Restructuring in the United States: A Geographical Perspective, 250-270. Lanham, MD: Rowman and Littlefield Publishers, 1999.

. "Internal Migration of the Foreign-Born in Canada." International Migration Review 30 (1996), 728-747.

Newbold, K.B., and K.L. Liaw. "Characterization of Primary, Return and Onward Interprovincial Migration in Canada: Overall and Age-Specific Patterns." Canadian Journal of Regional Science 13 (1990), 17-34.

" "Return and Onward Interprovincial Migration through Economic Boom and Bust in Canada, from 1976-81 to 1981-86." Geographical Analysis 26 (1994), 228-245.

Newbold, K.B., and M. Bell. "Return and Onwards Migration in Canada and Australia: Evidence from Fixed Interval Data." International Migration Review, 2001 (forthcoming).

Olson, S.H., and A. Kobayashi. "The Emerging Ethnocultural Mosaic." In L.S. Bourne and D. Ley (eds.) The Changing Social Geography of Canadian Cities, 138-152. Montreal: McGill-Queen's University Press, 1993.

Rogerson, P.A. "Migration Analysis Using Data with Time Intervals of Differing Widths." Papers of the Regional Science Association 68 (1990), 97-106.

Statistics Canada. Canada Year Book 1999. Ottawa, 1999.

Walker, R., and M. Hannan. "Dynamic Settlement Processes: The Case of US Immigration." The Professional Geographer 41 (1989), 172-183. 
